\title{
Further constraints for the Plio-Pleistocene geomagnetic field strength: New results from the Los Tuxtlas volcanic field (Mexico)
}

\author{
Luis M. Alva-Valdivia, Avto Goguitchaichvili, and Jaime Urrutia-Fucugauchi \\ Laboratorio de Paleomagnetismo y Geofisica Nuclear, Instituto de Geofísica, UNAM, Ciudad Universitaria, 04510 México, D.F., México
}

(Received October 30, 2000; Revised June 8, 2001; Accepted June 12, 2001)

\begin{abstract}
A rock-magnetic, paleomagnetic and paleointensity study was carried out on 13 Plio-Pleistocene volcanic flows from the Los Tuxtlas volcanic field (Trans Mexican Volcanic Belt) in order to obtain some decisive constraints for the geomagnetic field strength during the Plio-Pleistocene time. The age of the volcanic units, which yielded reliable paleointensity estimates, lies between 2.2 and $0.8 \mathrm{Ma}$ according to the available $\mathrm{K} / \mathrm{Ar}$ radiometric data. Thermomagnetic investigations reveal that remanence is carried in most cases by Ti-poor titanomagnetite, resulting from oxy-exsolution that probably occurred during the initial flow cooling. Unblocking temperature spectra and relatively high coercivity point to 'small' pseudo-single domain magnetic grains for these (titano)magnetites. Single-component, linear demagnetization plots were observed in most cases. Six flows yield reverse polarity magnetization, five flows are normally magnetized, and one flow shows intermediate polarity magnetization. Evidence of a strong lightning-produced magnetization overprint was detected for one site. The mean pole position obtained in this study is Plat $=83.7^{\circ}$, Plong $=178.1^{\circ}, K=36, A_{95}=8.1^{\circ}, N=10$ and the corresponding mean paleodirection is $I=31.3^{\circ}, D=352^{\circ}, k=37, \alpha_{95}=8.2^{\circ}$, which is not significantly different from the expected direction estimated from the North American apparent polar wander path. Thirty-nine samples were pre-selected for Thellier palaeointensity experiments because of their stable remanent magnetization and relatively weak-within-site dispersion. Only 21 samples, coming from four individual basaltic lava flows, yielded reliable paleointensity estimates with the flow-mean virtual dipole moments (VDM) ranging from 6.4 to $9.1 \times 10^{22} \mathrm{Am}^{2}$. Combining the coeval Mexican data with the available comparable quality Pliocene paleointensity results yield a mean VDM of $6.4 \times 10^{22}$ $\mathrm{Am}^{2}$, which is almost $80 \%$ of the present geomagnetic axial dipole. Reliable paleointensity results for the last $5 \mathrm{Ma}$ are still scarce and are of dissimilar quality. Additional high-quality absolute intensity determinations are needed to better constraint the geomagnetic field strength during the Plio-Pleistocene time.
\end{abstract}

\section{Introduction}

Determination of the absolute intensity of the Earth's magnetic field in the past is decisive for understanding the processes in the core that gave rise to the geomagnetic field and how and why the Earth's magnetic field reverses polarity. Moreover, variation of paleointensity over geologic time may indicate modulation of geodynamo action in the core by the convective state in the lower mantle. It also carries information about the rates of sea-floor spreading, hot-spot volcanism, the Earth's tectonic cycle, and true polar wander.

Glatzmaier et al. (1999) and Coe et al. (2000) recently suggested that absolute intensity should be a fundamental constraint in numerical models that promise to provide unprecedented insight into the operation of the geodynamo. Despite about 40 years of research, paleointensity data are scarce (Perrin and Shcherbakov, 1997) and they cannot be yet used to document a long-term variation in the intensity of the Earth's magnetic field through geological time. The major reason for the small number of determinations is that paleointensity is the most difficult component of the magnetic field to determine and the failure rate is often large,

Copy right (C) The Society of Geomagnetism and Earth, Planetary and Space Sciences (SGEPSS); The Seismological Society of Japan; The Volcanological Society of Japan; The Geodetic Society of Japan; The Japanese Society for Planetary Sciences. generally in the order of $80 \%$ (Kosterov and Prévot, 1998). Prévot et al. (1990) first underlined the existence of a relatively low paleointensity field during the Mesozoic time. However, little is known about the transition mode between the Mesozoic low and present-day 'high' field, largely because of the limited amount of reliable data available. Based on the study of submarine basaltic glass, Juarez and Tauxe (2000) argued that the geomagnetic field strength was also substantially low for the last $5 \mathrm{Ma}$ (and maybe for the last $160 \mathrm{Ma}$ ) which is in disagreement with the value of approximately $8 \times 10^{22} \mathrm{Am}^{2}$ often quoted for the last $5 \mathrm{Ma}$ (Goguitchaichvili et al., 1999a). The excellent technical quality of paleointensity data obtained from basaltic glasses, first underlined by Pick and Tauxe (1993), may not be by itself proof of the geomagnetic validity of the paleostrength found (Goguitchaichvili et al., 1999b). Keeping this in mind, more reliable data are required for the last $5 \mathrm{Ma}$. In this paper, we report a detailed rock-magnetic, paleomagnetic and paleointensity study from 13 Plio-Pleistocene lava flows from the Los Tuxtlas volcanic field (Mexico). The previous detailed geochronology study (Nelson and GonzalezCaver, 1992) of the Los Tuxtlas field was particularly encouraging for the paleomagnetic project. 


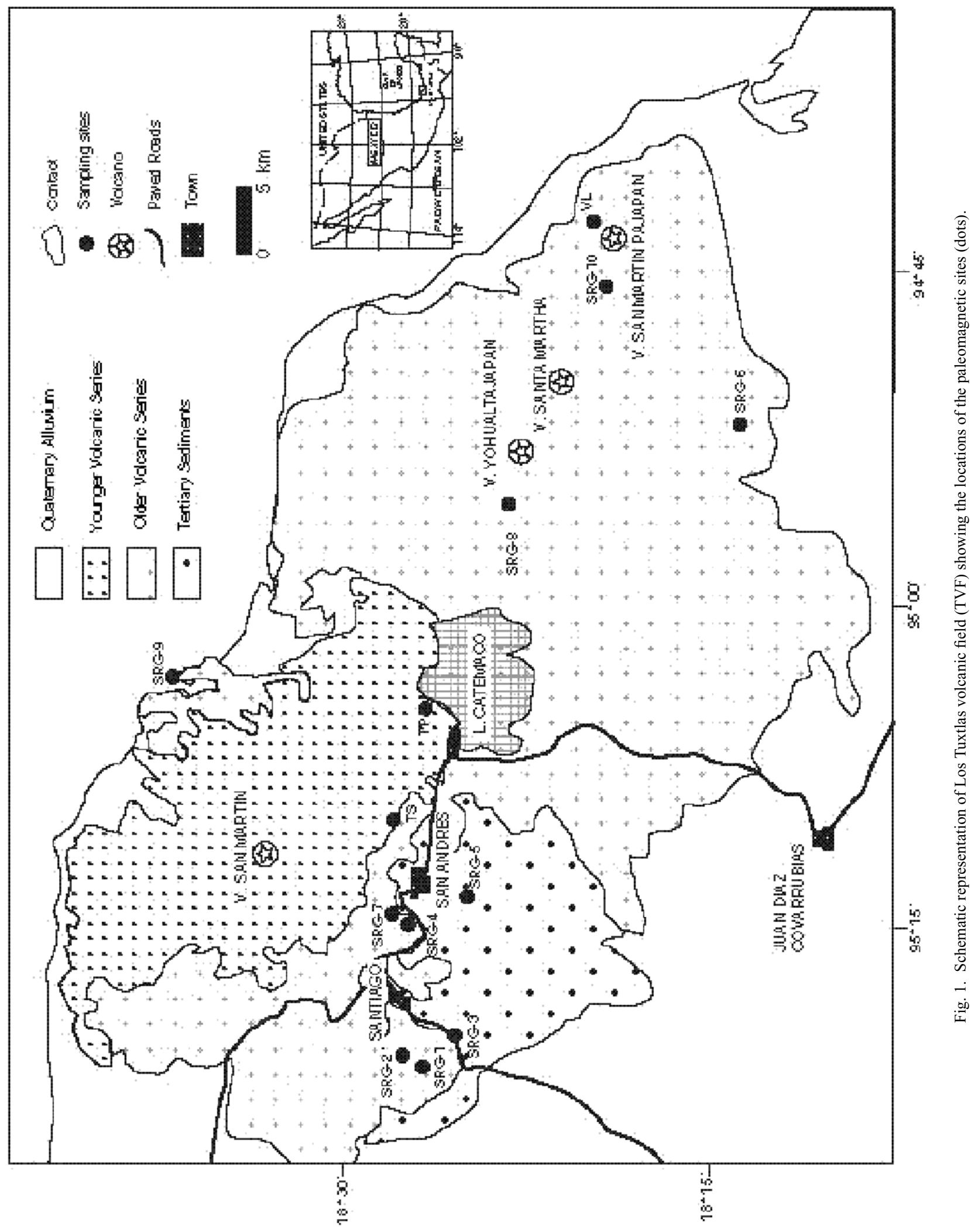


Table 1. Paleodirectional results from TVF Plio-Pleistocene basaltic rocks: $N$ : Number of treated samples, $n$ : number of samples used for calculation, Dec: Declination, Inc: Inclination, $k$ and $\alpha_{95}$ : Precision parameter and radius of confidence cone, Plat/Plong: Latitude/Longitude of VGP position. Age: $\mathrm{K}-\mathrm{Ar}$ ages in My (Nelson and Gonzalez-Caver, 1992).

\begin{tabular}{ccccccccc}
\hline Site & $n / N$ & \multicolumn{1}{c}{ Dec } & \multicolumn{1}{c}{ Inc } & \multicolumn{1}{c}{$k$} & $\alpha_{95}$ & Plat & Plong & Age (My) \\
\hline TS & $10 / 10$ & 1.6 & 18.2 & 86 & 5.2 & 74.9 & 1.4 & $0.8 \pm 0.1$ \\
TP & $7 / 8$ & 358.9 & 37.1 & 79 & 6.3 & 87.3 & 242.8 & $0.8 \pm 0.1$ \\
SRG1 & $5 / 6$ & 334.7 & 27.1 & 56 & 8.4 & 65.4 & 169.7 & $2.6 \pm 0.2$ \\
SRG2 & $5 / 6$ & 343.9 & 43.3 & 108 & 7.4 & 73.5 & 203 & $2.6 \pm 0.2$ \\
SRG3 & $7 / 7$ & 172.1 & -29.4 & 91 & 4.8 & -82.1 & 339.1 & $2.2 \pm 0.3$ \\
SRG4 & $4 / 6$ & 155.8 & -20.6 & 31 & 10.7 & -65.5 & 350.8 & $2.2 \pm 0.3$ \\
SRG5 & $7 / 7$ & 182 & -18.9 & 171 & 4.6 & -81.3 & 251.9 & $3.1 \pm 0.2$ \\
SRG6 & $6 / 7$ & 173.9 & -30.4 & 72 & 7 & -83.9 & 338.3 & $1.4 \pm 0.2$ \\
SRG7 & $6 / 7$ & 184.9 & -41.6 & 63 & 8.5 & -82.7 & 122.7 & $2.2 \pm 0.2$ \\
SRG8 & $9 / 9$ & 172.2 & -42.6 & 166 & 4.3 & -80.3 & 38.2 & $1.0 \pm 0.1$ \\
SRG9 & $2 / 6$ & 323.3 & 5.7 & - & - & 50.9 & 156.2 & $6.9 \pm 0.8$ \\
VL & $5 / 6$ & 232.4 & -17.9 & 36 & 12.3 & -38.5 & 177.7 & $1.5 \pm 0.2$ \\
\hline
\end{tabular}

\section{Sampling Details}

The Los Tuxtlas Volcanic Field (TVF) is located on Mexico's Gulf Coast in the southern part of the state of Veracruz (Fig. 1). Volcanism began about $7 \mathrm{Ma}$ ago (Nelson et al., 1995) and continued to recent times with historical eruptions in AD 1664 and $\mathrm{AD}$ 1793. In total, about $800 \mathrm{~km}^{3}$ of lava has been erupted in the TVF in the last $7 \mathrm{Ma}$ (Nelson and Gonzalez-Caver, 1992). This gives a magma output rate of about $0.1 \mathrm{~km}^{3} / 1000$ years. The volcanic units are composed mainly of alkali basalts and less commonly calc-alkaline basaltic andesites and andesites. There has been much debate about whether magmatism in the TVF is directly related to subduction of the Cocos Plate beneath southern Mexico or is related to extensional tectonics along the Gulf of Mexico (Freidlaender and Sonder, 1923; Pichler and Weyl, 1976; Thorpe, 1977; Cantagrel and Robin, 1979; Nelson and Gonzalez-Caver, 1992). However, there is now general agreement that despite the alkaline character of the magmas erupted in the TVF, magmatism appears to be related to subduction. Low-degree melts of the subductionmodified mantle apparently reach the surface in the TVF due to an extensional stress regime that has allowed their passage to the surface (Nelson et al., 1995).

Our sampling strategy was largely conditioned by the studies of Nelson and Gonzalez-Caver (1992) and Nelson et al. (1995), since we sampled only sites with available radiometric dating information (Table 1). In total, 95 oriented samples belonging to 13 individual lava flows (Fig. 1) were collected. The samples were distributed throughout each flow both horizontally and vertically in order to minimize the effects of block tilting and lightning. In general, samples were obtained at the very bottom of flows in the hope of collecting samples with the finest grains of material. Cores were obtained with a gasoline-powered portable drill and then in most cases, oriented with a magnetic compass (after testing that it was not affected by the remanent magnetization of the outcrop).

\section{Magnetic Experiments}

\subsection{Demagnetization}

The remanent magnetization of six to ten samples from each lava flow (Table 1) was measured with a JR-5a (AGICO LTD) spinner magnetometer (sensitivity $\sim 10^{-9} \mathrm{Am}^{2}$ ) at the paleomagnetic laboratory of National University of Mexico (UNAM). Measurements were recorded after stabilization of the remanence in this magnetometer. Both alternating field (AF) demagnetization using a laboratory made AFdemagnetizer and stepwise thermal (mainly) demagnetization up to $575-675^{\circ} \mathrm{C}$ using a non-inductive Schonstedt furnace, were carried out. During thermal demagnetization, the low-field susceptibility at room temperature was measured after each step with a Bartington susceptibility meter.

In most of the studied units, only one paleomagnetic component could be recognized (Figs. 2(a) and (b)). Small secondary components were easily removed applying $200^{\circ} \mathrm{C}$ or $12-20 \mathrm{mT}$. The greater part of the remanent magnetization, in most cases was removed at temperatures of between 490 and $550^{\circ} \mathrm{C}$, indicating low-Ti titanomagnetites as being responsible for magnetization. The median destructive fields (MDF) range mostly from 40 to $60 \mathrm{mT}$, suggesting 'small' pseudo-single domain grains as remanent magnetization carriers (Dunlop and Özdemir, 1997). One site (SRG10) of the 13 sampled, was characterized by unusually high intensity (more than several hundred $\mathrm{A} / \mathrm{m}$ ) and scattered NRM directions. Both factors may point to strong lightning-produced magnetization overprint. These samples were rejected for further paleomagnetic analysis.

A characteristic magnetization direction was determined by the least-squares method (Kirschvink, 1980); with four to nine points being taken in the principal component analysis for this determination. The obtained directions were averaged by unit and the statistical parameters calculated assuming a Fisherian distribution. Average unit directions were rather precisely determined (Table 1; Fig. 3); almost all $\alpha_{95}$ are less than $10^{\circ}$, except for site VL. 

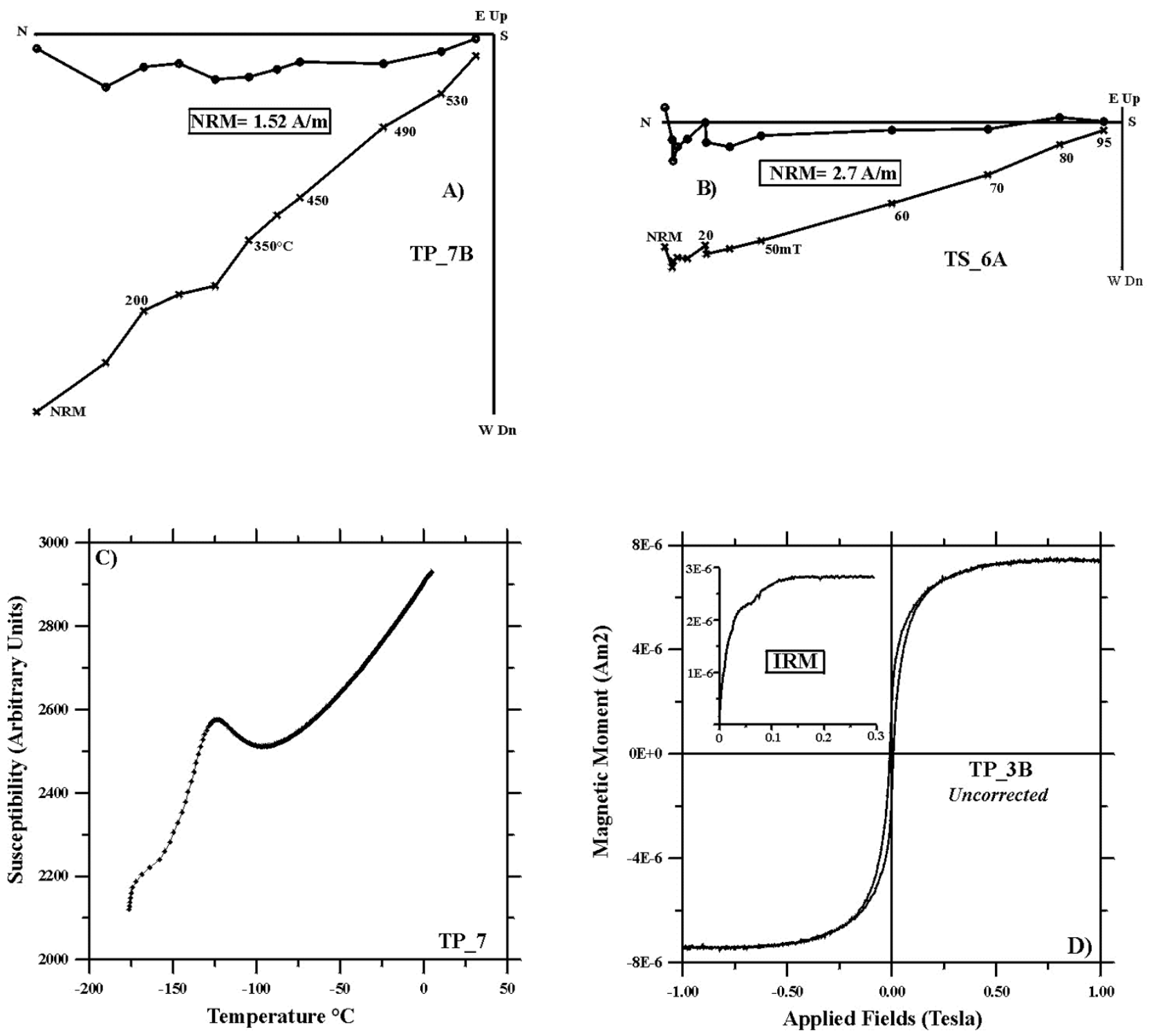

Fig. 2. Summary of the magnetic characteristics of the typical samples, selected for Thellier paleointensity experiments. (A) and (B) Orthogonal vector plots of stepwise thermal and alternating field demagnetization (stratigraphic co-ordinates). The numbers refer to temperatures in ${ }^{\circ} \mathrm{C}$ or peak alternating fields in $\mathrm{mT}$. o-projections into the horizontal plane, $\times$-projections into the vertical plane. (C) Susceptibility versus temperature curves recorded from about $-185^{\circ} \mathrm{C}$ to room temperature. (D) Examples of hysteresis loops (uncorrected) of small chip samples and corresponding isothermal remanence acquisition curve (see also the text).

\subsection{Low temperature susceptibility curves}

Low-field and low-temperature susceptibility measurements ( $k$ - $T$ curves) in the air were carried out using a Highmoore susceptibility bridge equipped with a furnace in order to identify the magnetic minerals responsible for magnetization. Initial susceptibility was recorded from about $\sim-185^{\circ} \mathrm{C}$ to room temperature.

In almost all cases, the curves show a rather monotonic increase from about $-185^{\circ} \mathrm{C}$ to room temperature, yielding a quite well-defined inflection point (Fig. 2(c)) at about $-135^{\circ} \mathrm{C}$, which probably indicates the Verwey transition, characteristic of almost pure magnetite or titanium-poor titanomagnetite resulting from oxy-exsolution (Ozdemir et al., 1993). Alternatively, similar behavior may also correspond to non-stoichiometric (partially oxidized) magnetite (Dunlop and Özdemir, 1997).

\subsection{Hysteresis measurements}

Hysteresis measurements at room temperature were performed on all studied sites using the AGFM 'Micromag' apparatus of the paleomagnetic laboratory in Mexico City in fields up to 1 Tesla. The saturation remanent magnetization $\left(J_{r s}\right)$, the saturation magnetization $\left(J_{s}\right)$, and the coercive force $\left(H_{c}\right)$ were calculated after correction for the paramagnetic contribution. The coercivity of the remanence $\left(H_{c r}\right)$ was determined by applying a progressively increasing backfield after saturation. A typical hysteresis plot is reported in Fig. 2(d). The curves are quite symmetrical in all cases. Near the origin, a slightly wasp-waisted loop may be detected which probably points to the magnetic minerals of distinct coercivities (Tauxe et al., 1996). Judging from the ratios of the hysteresis parameters $\left(H_{c r} / H_{c}\right.$ ranges between 2.2 and 3.5 and $J_{r s} / J_{s}$ varies from 0.18 to 0.29 ), it seems 


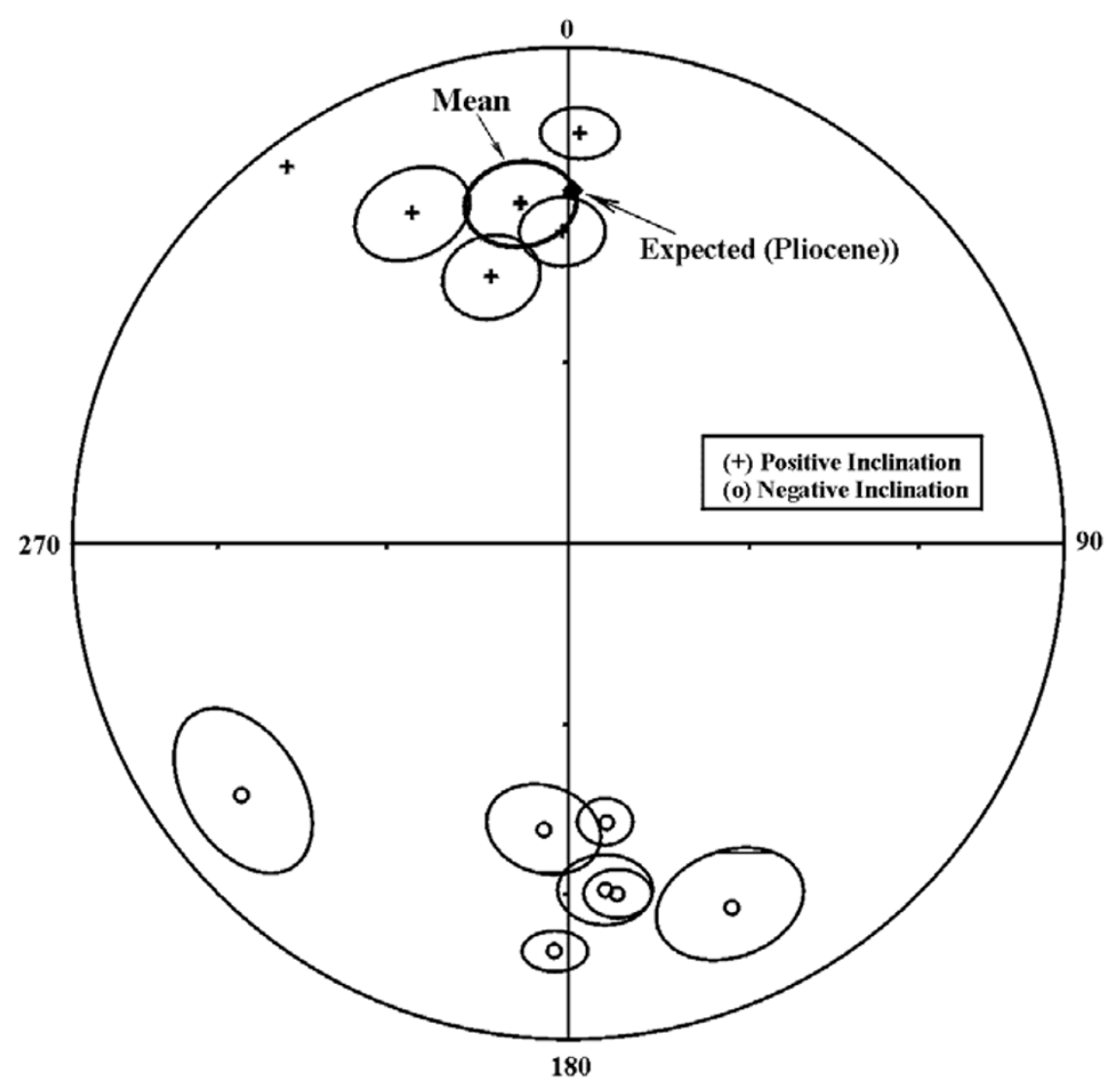

Fig. 3. Equal area projections of the flow mean characteristic paleodirections for TVF. Circles/Crosses denote to the negative/positive inclinations.

that all samples fall in the pseudo-single domain (PSD) grain size region (Day et al., 1977), probably indicating a mixture of multidomain (MD) and a significant amount of single domain (SD) grains. Isothermal remanence (IRM) acquisition curves (Fig. 2(d)) were found to be very similar for all samples. Saturation is reached in moderate fields of the order of 100-120 $\mathrm{mT}$, which points to some spinels as remanence carriers.

\subsection{Paleointensity}

Paleointensity experiments were performed using the Thellier method (Thellier and Thellier, 1959) in its modified form (Coe et al., 1978). The heatings and coolings were made in the air and in the laboratory field set to 50 or sometimes 40 microtesla. Nine temperature steps were distributed between room temperature and $550^{\circ} \mathrm{C}$. The pTRM/NRM checks (so-called pTRM checks) were performed only three times (Fig. 4) in order to avoid additional heatings, which may significantly alter the remanence.

Following the paleodirectional and rock-magnetic results, altogether 39 samples belonging to seven cooling units, yielding stable, one component magnetization with blocking temperatures compatible to 'near' magnetite phase and with relatively high MDF values, were selected for paleointensity experiments. Five sites (SRG1, SRG4, SRG7, SRG9 and VL) were not selected because of relatively high directional dispersion $\left(\alpha_{95}\right.$ above $\left.8^{\circ}\right)$.

Paleointensity data are reported on the classical AraiNagata (Nagata et al., 1963) plot in Fig. 4 and the results are given in Table 2 . We accepted only determinations that ful- fill the following criteria: (1) determination obtained from at least 5 NRM-TRM points corresponding to a NRM fraction larger than 1/3 (Table 2), (2) quality factor (Coe et al., 1978) of about 5 or more, and (3) positive 'pTRM' checks, i.e. the deviation of 'pTRM' checks was less than $15 \%$. Directions of NRM remaining at each step obtained from the paleointensity experiments are reasonably linear and point to the origin. No deviation of NRM in the remaining directions towards the direction of the applied laboratory field was observed.

Finally, only 21 samples, coming from four individual basaltic lava flows, yielded acceptable paleointensity estimates. For these samples, the NRM fraction $f$ used for determination ranges between 0.46 to 0.91 and the quality factor $q$ from 4.6 to 27.9 being generally greater than 5. For the remaining samples, the main reason for failure of Thellier paleointensity experiments was the typical 'concave-up' behavior (Dunlop and Özdemir, 1997). An important loss of NRM (natural remanent magnetization) was observed without any noticeable TRM (thermoremanent magnetization) acquisition. This phenomenon can be due to irreversible variations of coercive force (Kosterov and Prévot, 1998) at low temperature and can be interpreted as the transformation from a single-domain 'metastable' state to a polydomain state which results in a large NRM loss without any correlated TRM acquisition during the subsequent cooling.

\section{Discussion and Main Results}

We consider the characteristic paleomagnetic directions 

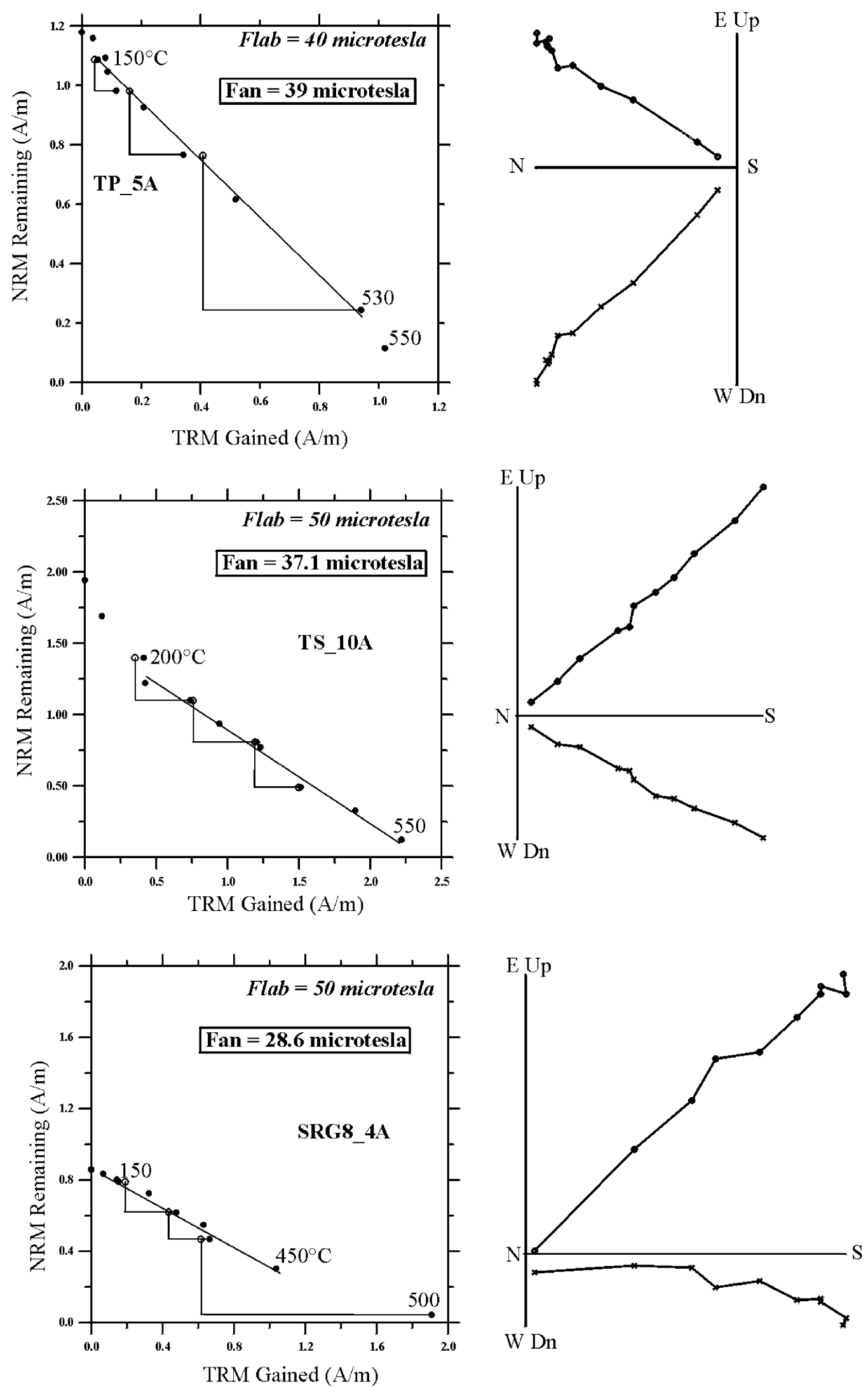

Fig. 4. The representative NRM-TRM plots and associated orthogonal diagrams from Los Tuxtlas samples. We used the same notations in the orthogonal diagrams as in Fig. 2. 
Table 2. Paleointensity results from the TVF, $n$ is the number of NRM-TRM points used for paleointensity determination, $T_{\min }-T_{\max }$ is the temperature interval used, $f, g$ and $q$ are the fraction of extrapolated NRM used, the gap factor, and the quality factor (Coe $e t$ al., 1978) respectively. Fa is the individual paleointensity estimate with associated error, Fe is site mean paleointensity, VDM and VDMe are individual and average virtual dipole moments.

\begin{tabular}{|c|c|c|c|c|c|c|c|c|c|}
\hline Sample & $\begin{array}{c}T_{\min }-T_{\max } \\
\left({ }^{\circ} \mathrm{C}\right)\end{array}$ & $n$ & $f$ & $g$ & $q$ & $\begin{array}{c}\text { Fa (error) } \\
(\mu \mathrm{T})\end{array}$ & $\begin{array}{c}\mathrm{VDM} \\
\left(10^{22} \mathrm{Am}^{2}\right)\end{array}$ & $\begin{array}{c}\mathrm{Fe} \\
\text { (s.d.) }\end{array}$ & $\begin{array}{l}\text { VDMe } \\
\text { (s.d.) }\end{array}$ \\
\hline TS_1A & $150-530$ & 9 & 0.72 & 0.68 & 7.8 & $44.3 \pm 2.4$ & 11 & $36.5 \pm 5.2$ & $9.1 \pm 1.3$ \\
\hline TS_4A & $250-530$ & 7 & 0.74 & 0.79 & 14.2 & $42.4 \pm 1.8$ & 10.6 & & \\
\hline TS_6B & $250-490$ & 6 & 0.63 & 0.75 & 7.9 & $35.4 \pm 2.1$ & 8.8 & & \\
\hline TS_7B & $300-530$ & 6 & 0.78 & 0.74 & 8.7 & $30.1 \pm 1.9$ & 7.5 & & \\
\hline TS_8B & $150-550$ & 10 & 0.91 & 0.79 & 27.9 & $31.7 \pm 0.8$ & 7.9 & & \\
\hline TS_9A & $300-530$ & 6 & 0.67 & 0.73 & 13.9 & $34.6 \pm 1.4$ & 8.6 & & \\
\hline TS_10A & $200-550$ & 9 & 0.87 & 0.86 & 17.3 & $37.1 \pm 1.6$ & 9.2 & & \\
\hline TP_1A & $250-530$ & 7 & 0.71 & 0.82 & 11.9 & $44.2 \pm 2.1$ & 9.7 & $38.1 \pm 7.2$ & $8.4 \pm 1.6$ \\
\hline $\mathrm{TP} 2 \mathrm{~A}$ & $250-530$ & 7 & 0.66 & 0.8 & 10.8 & $46.6 \pm 2.2$ & 10.3 & & \\
\hline TP_3A & $200-530$ & 8 & 0.59 & 0.82 & 13.6 & $43.8 \pm 1.6$ & 9.6 & & \\
\hline TP_4A & $300-490$ & 5 & 0.46 & 0.73 & 6.8 & $28.6 \pm 1.4$ & 6.3 & & \\
\hline TP_5A & $150-530$ & 9 & 0.82 & 0.76 & 20.1 & $39.0 \pm 1.3$ & 8.6 & & \\
\hline TP_7A & $150-490$ & 8 & 0.57 & 0.79 & 5.8 & $29.7 \pm 2.1$ & 6.6 & & \\
\hline TP_10A & $150-490$ & 8 & 0.66 & 0.83 & 6.7 & $35.8 \pm 2.4$ & 7.9 & & \\
\hline SRG3_2A & $200-530$ & 6 & 0.72 & 0.74 & 8.6 & $24.9 \pm 1.5$ & 5.8 & $34.7 \pm 7.3$ & $8.1 \pm 1.7$ \\
\hline SRG3_3A & $150-530$ & 7 & 0.68 & 0.83 & 4.6 & $33.5 \pm 1.8$ & 7.8 & & \\
\hline SRG3_5A & $150-530$ & 7 & 0.62 & 0.69 & 12.1 & $39.1 \pm 2.0$ & 9.1 & & \\
\hline SRG3_6 & $150-530$ & 7 & 0.75 & 0.73 & 11.3 & $41.5 \pm 2.1$ & 9.7 & & \\
\hline SRG8_4A & $100-450$ & 8 & 0.61 & 0.8 & 9.1 & $28.6 \pm 1.5$ & 6 & $30.6 \pm 4.3$ & $6.4 \pm 0.9$ \\
\hline SRG8_5A & $200-530$ & 6 & 0.73 & 0.71 & 17.8 & $35.6 \pm 1.1$ & 7.5 & & \\
\hline SRG8_9A & $200-490$ & 5 & 0.52 & 0.7 & 4.8 & $27.7 \pm 1.8$ & 5.8 & & \\
\hline
\end{tabular}

determined in this study to be of primary TRM origin. This is supported by the occurrence of antipodal normal and reversed polarity directions. In addition, thermomagnetic investigations show that the remanence is carried in most cases by Ti-poor titanomagnetite, resulting from the oxi-exsolution of the original titanomagnetite during the initial flow cooling, which probably indicates the thermoremanent origin of a primary magnetization. Moreover, unblocking temperature spectra and the relatively high coercivity point to 'small' pseudo-single domain magnetic structure grains being responsible for remanent magnetization. Single-component, linear demagnetization plots were observed in most cases.

Six sites yielded reverse polarity magnetization and 5 are normally magnetized. Only one unit (site VL) showed intermediate polarity magnetization. It cannot be ascertained that site SRG9 has normal polarity magnetization because it is represented only by two samples. The mean paleomagnetic pole position calculated after discarding sites VL and SRG9, is Plat $=83.7^{\circ}$, Plong $=178.1^{\circ}, \mathrm{K}=36$, $A_{95}=8.1^{\circ}, N=10$ and the corresponding mean paleodirection is $I=31.3^{\circ}, D=352^{\circ}, k=37, \alpha_{95}=8.2^{\circ}$ (Fig. 3 ). There directions are in reasonably good agreement with the expected paleodirections for Pliocene time, as derived from the reference poles given by Besse and Courtillot (1991) for North America (see also Alva-Valdivia et al., 2000). This suggests that no major tectonic deformation occurred in the TVF area after about $3 \mathrm{Ma}$. More robust directional data are required to better constraint the paleotectonic evolution of TVF.

Thellier paleointensity experiments were carried out on 39 samples from the Pliocene TVF volcanic lava flows. Twenty-one samples from four individual basaltic lava flows yielded acceptable paleointensity estimates. The site mean paleointensities range from $30.6 \pm 4.3$ to $38.1 \pm 7.2 \mu \mathrm{T}$ and the VDMs range from 6.4 to $9.1 \times 10^{22} \mathrm{Am}^{2}$. The amplitude of VDM variation we obtained is reasonably large and most probably belonged to the geomagnetic field rather than some experimental artifact.

Although our results are not numerous, some credit should be given because of good technical quality determination attested by the reasonably high Coe et al.' quality factors. The within-site dispersion we found in our study (standard deviation on the order of $15-20 \%$ ) is common for absolute paleointensity study (Selkin and Tauxe, 2000). We have no objective reasons to reject any of our individual determinations in order to reduce the dispersion observed. Moreover, let us note that a small curvature on Arai-Nagata 
Table 3. Average virtual dipole moment $\left(10^{22} \mathrm{Am}^{2}\right)$ for various regions during the Pliocene (from Thellier paleointensity data, see the text). $N$ refers to the number of cooling units used to calculate the average VDM. The pre or post-intermediate paleointensities are shown in italics.

\begin{tabular}{lcccll}
\hline \multicolumn{1}{c}{ Region } & $\begin{array}{c}\text { Age } \\
(\mathrm{My})\end{array}$ & $N$ & $\begin{array}{c}\text { VDM } \\
\left(10^{22} \mathrm{Am}^{2}\right)\end{array}$ & S.D. & \multicolumn{1}{c}{ Reference } \\
\hline Oceanic Basalts* & $3.9-2$ & 3 & 5.2 & 1.8 & Juarez and Tauxe (2000) \\
Oceanic Basalts* & $3.9-0.4$ & 3 & 4.9 & 2.8 & Selkin and Tauxe (2000) \\
East Eifel & $0.49-0.35$ & 7 & 6.5 & 1.3 & Schnepp (1996) \\
Georgia* & $3.8-3.6$ & 3 & 6.8 & 1.1 & Goguitchaichvili et al. (2000a) \\
Mexico* & $2.2-0.8$ & 4 & 8 & 1.1 & This study \\
SW Iceland & 2.58 & 3 & 8.5 & 7.2 & Tanaka et al. (1995) \\
SW Iceland* & 2.11 & 14 & 6.2 & 2.4 & Goguitchaichvili et al. (1999a) \\
West Eifel & $0.55-0.4$ & 24 & 6.1 & 2 & Schnepp and Hradetzky (1994) \\
Georgia* & 3.6 & 6 & 5.5 & 2.3 & Goguitchaichvili et al. (2000b) \\
\hline Total & & 67 & 6.4 & 1.2 & \\
\hline
\end{tabular}

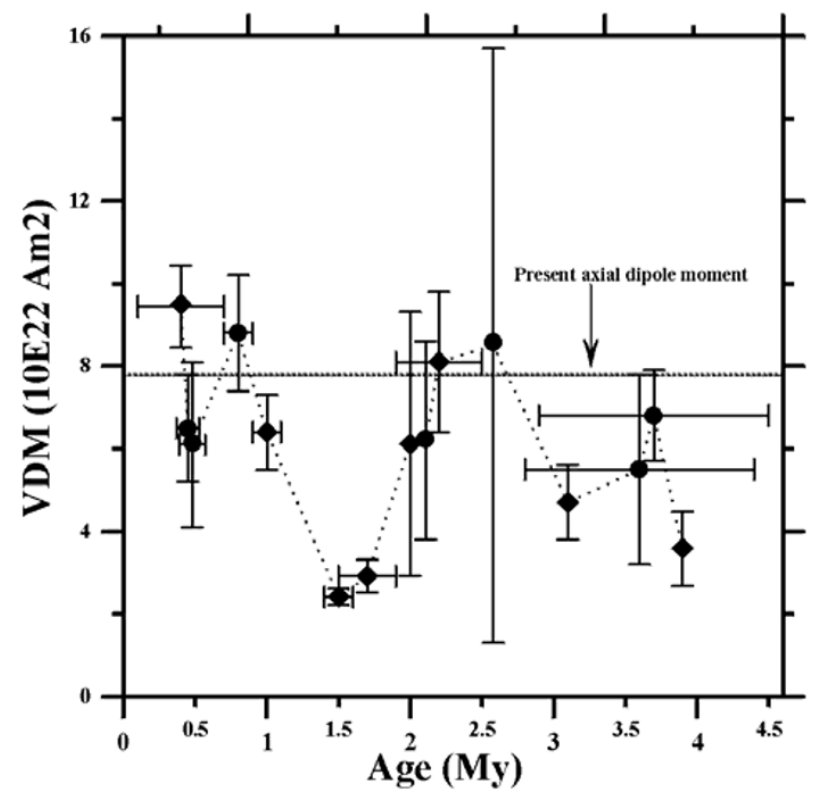

Fig. 5. Virtual dipole moments against the ages of volcanic units in My according to selected absolute intensity data (see also the text and Table 3). Squares denote the results from single cooling units while dots represent the mean value of several consecutive lava flows. In some cases, the error bars for the ages are missing because of the absence of adequate information.

curves (observed in some cases) at low temperatures (Fig. 4, Samples TP_5a and TS_10a) is most probably not significant. The temperature interval from 150 to $250^{\circ} \mathrm{C}$ is generally admitted as being the unblocking temperature spectra of viscous remanent magnetization. Thus we can allow some non-significant 'irregularities' at this interval.

There are not enough data to discuss VDM variation through the Pliocene time and it is necessary to combine the Mexican results with previously published estimates from the same period of time (Table 3 and Fig. 5). In our analyses of the Pliocene paleointensity data, we consider (1) only results obtained with the Thellier method for which positive pTRM checks attest the absence of alteration during heatings, (2) at least three determinations per unit, (3) quality factors (when available) of around five or more (these determinations are shown by stars in Table 3) and (4) no data from transitional polarity units. From about 800 PlioPleistocene determinations available in the IAGA database (so-called 'Montpellier 98 database' compiled by Mireille Perrin and Lisa Schnepp, see also Perrin et al., 1998) only 63 determinations fulfill these basic criteria. Twenty-three selected determinations come from studies published during last two years (Table 3; Fig. 5), and seven of them belong to basaltic glasses (Juarez and Tauxe, 2000; Selkin and Tauxe, 2000). Results from basaltic glasses correspond to the mean paleointensity from the same drill core. Four more absolute intensity determinations were obtained in this study. We also note that 47 determinations correspond to pre or post-intermediate geomagnetic fields. They are shown in italics in Table 3. Combination of the Mexican data with the absolute intensity results currently available for the PlioPleistocene show the VDM variation ranging from 2.41 to $9.45 \times 10^{22} \mathrm{Am}^{2}$ (Fig. 5) yielding a mean VDM of $6.4 \times 10^{22}$ $\mathrm{Am}^{2}$, which is about $80 \%$ of the present geomagnetic axial dipole $\left(7.8 \times 10^{22} \mathrm{Am}^{2}\right.$ after Barton et al., 1996). Reliable absolute paleointensity results for the last $5 \mathrm{Ma}$ are still scarce and of dissimilar quality. Additional high-quality determinations are needed to better document the geomagnetic field strength during the Pliocene.

Acknowledgments. The comments of Mireille Perrin, Graham Sherwood and Hidefumi Tanaka on an early version of this manuscript lead to significant improvements of the scientific content and English style of this paper. The financial support was provided by DGAPA IN-100100 and CONACYT J32727-T projects.

\section{References}

Alva-Valdivia, L. M., A. Goguitchaichvili, L. Ferrari, J. Rosas-Elguera, J. Urrutia-Fucugauchi, and J. J. Zamorano-Orozco, Paleomagnetic data from the Trans-Mexican Volcanic Belt: Implications for tectonics and volcanic Stratigraphy, Earth Planets Space, 52, 467-478, 2000.

Barton, C. E., R. Baldwin, D. Barraclough, S. Bushati, M. Chiappini, Y. Cohen, R. Coleman, G. Hulot, V. Kotze, V. Golovkov, A. Jackson, R. Langel, F. Lowes, D. McKnight, S. Macsmillan, L. Newitt, N. Peddie, J. Quinn, and T. Sabaka, International geomagnetic reference field, 1995 revision, Geophys. J. Int., 125, 318-321, 1996. 
Besse, J. and V. Courtillot, Revised and synthetic apparent polar wander paths of the African, Eurasian, North American and Indian Plates, and true polar wander since $200 \mathrm{Ma}$, J. Geophys. Res., 96, 4029-4050, 1991.

Cantagrel, J. and C. Robin, K-Ar dating on eastern Mexican volcanic rocks - relations between the andesitic and the alkaline provinces, J. Volcanol. Geotherm. Res., 5, 99-114, 1979.

Coe, R. S., S. Grommé, and E. A. Maniken, Geomagnetic paleointensities from radiocarbon-dated lava flows on Hawaii and the question of the Pacific nondipole low, J. Geophys. Res., 83, 1740-1756, 1978.

Coe, R., L. Hongre, and G. A., Glatzmaier, An examination of simulated geomagnetic reversals from a paleomagnetic perspective, Phil. Trans. Roy. Soc. London, Series A, 357, 1787-1813, 2000.

Day, R., M. Fuller, and V. A. Schmidt, Hysteresis properties of titanomagnetites: Grain-size and compositional dependence, Phys. Earth Planet. Int., 13, 260-267, 1977.

Dunlop, D. and Ö. Özdemir, Rock-Magnetism, fundamentals and frontiers, Cambrige University Press, 573 pp., 1997.

Glatzmaier, G. A., R. S. Coe, L. Hongre, and P. H. Roberts, The role of the Earth's mantle in controlling the frequency of geomagnetic reversals, Nature, 401, 885-890, 1999.

Friedlaender, I. and R. A. Sonder, Uber das vulkangebiet von San Martin Tuxtla in Mexiko, Zeitschrift fur vulkanologie, VII, 162-187, 1923.

Goguitchaichvili, A., M. Prévot, and P. Camps, No evidence for strong fields during the R3-N3 Icelandic geomagnetic reversals, Earth Planet. Sci. Lett., 167, 15-34, 1999a.

Goguitchaichvili, A., M. Prévot, J. M. Dautria, and M. Bacia, Thermodetrital and crystalline magnetizations in an Icelandic hyaloclastite, $J$. Geophys. Res., 104, 29219-29239, 1999b.

Goguitchaichvili, A., L. Alva Valdivia, J. Morales, and J. Gonzalez, New Contributions to the Early Pliocene geomagnetic strength, Geofisica Internacional, 3, 277-284, 2000a.

Goguitchaichvili, A., P. Camps, and J. Urrutia-Fucugauchi, On the features of the geodinamo following reversals and excursions: by absolute geomagnetic intensity data, Phys. Earth Planet. Int., 124, 81-93, 2000b.

Juarez, M. T. and L. Tauxe, The intensity of the time-averaged geomagnetic field: the last 5 Myr, Earth Planet. Sci. Lett., 175, 169-180, 2000.

Kirschvink, J. L., The least-square line and plane and analysis of palaeomagnetic data, Geophys. J. R. Astron. Soc., 62, 699-718, 1980.

Kosterov, A. and M. Prévot, Possible machanisms causing failure of thellier paleointensity experiments: results of rock magnetic study of the Lesotho basalt, Southern Africa. Geophys. J. Int., 134, 554-572, 1998.

Nagata, T., R. M. Fisher, and K. Momose, Secular variation of the geomagnetic total force during the last 5000 years, J. Geophys. Res., 68 , 5277-5281, 1963.

Nelson, S. A. and E. Gonzalez-Caver, Geology and K-Ar dating of the Tuxtla volcanic field, Veracruz, Mexico. Bull. Volcanol., 55, 85-89,
1992

Nelson, S. A., E. Gonzalez-Caver, and T. K. Kyser, Constraints on the origin of alkaline and calc-alkaline magmas from the Tuxtla volcanic field, Veracruz, Mexico. Contrib. Mineral. Petrol., 122, 191-211, 1995.

Ozdemir, O., D. Dunlop, and B. M. Moskowitz, The effect of oxidation on the Verwey transition in magnetite, Geophys. Res. Lett., 20, 1671-1674, 1993.

Perrin, M. and V. P. Shcherbakov, Paleointensity of the earth magnetic field for the past $400 \mathrm{My}$ : evidence for a dipole structure during the Mesozoic low, J. Geomag. Geoelectr., 49, 601-614, 1997.

Perrin, M., E. Schnepp, and V. Shcherbakov, Paleointensity database updated, EOS, 79, 198, 1998.

Pichler, H. and R. Weyl, Quaternary alkaline volcanic rocks in eastern Mexico and Central America, Munster Forsch. Geol. Palant., 38-39, 159178, 1976.

Pick, T. and L. Tauxe, Geomagnetic paleointensities during the Cretaceous normal superchron measured using submarine basaltic glass, Nature, 366, 238-242, 1993.

Prévot, M., M. E. M. Derder, J. McWilliams, and J. Thompson, Intensity of the Earth's magnetic field: evidence for a Mesozoic dipole low, Earth Planet. Sci. Lett., 97, 129-139, 1990.

Schnepp, E., Geomagnetic paleointensities derived from volcanic rocks of the Quaternary East Eifel volcanic field, Germany, Phys. Earth Planet. Int., 94, 23-41, 1996.

Schnepp, E. and H. Hradetzky, Combined paleointensity and Ar/Ar age spectrum data from volcanic rocks of the West Eifel field (Germany): Evidence for an early Brunhes geomagnetic excursion, J. Geophys. Res., 99, 9061-9072, 1994.

Selkin, P. A. and L. Tauxek, Long-term variations in palaeointensity, Phil. Trans. R. Soc. Lond. A, 358, 1065-1088, 2000.

Tanaka, H., M. Kono, and S. Kaneko, Paleosecular variation of direction and intensity from two Pliocene-Pleistocene lava sections in Southwestern Iceland, J. Geomag. Geoelectr., 47, 89-102, 1995.

Tauxe, L., T. A. T. Mullender, and T. Pick, Pot-bellies, wasp-waists and superparamagnetism in magnetic hysteresis, J. Geophys. Res., 95, 12337$12350,1996$.

Thellier, E. and O. Thellier, Sur l'intensité du champ magnétique terrestre dans le passé historique et géologique, Ann. Géophysique, 15, 285-376, 1959.

Thorpe, R. S., Tectonic significance of alkaline volcanism in eastern Mexico, Tectonophys., 40, T19-T26, 1977.

L. M. Alva-Valdivia (e-mail: lalva@tonatiuh.igeofcu.unam.mx), A. Goguitchaichvili, and J. Urrutia-Fucugauchi 